\title{
Pyogenic Granuloma of Nasal Septum: A Case Report and Review of Literature
}

\author{
Ramabhadraiah Anil Kumar*, Myle Mahesh Babu, Palegar Rayadurga Venkatarajamma, \\ Urvashi Mishra
}

Department of ENT, Bangalore Medical College \& Research Institute, Bangalore, India

Email: ${ }^{*}$ dranil24@yahoo.com

Received 7 May 2014; revised 5 June 2014; accepted 3 July 2014

Copyright (C) 2014 by authors and Scientific Research Publishing Inc.

This work is licensed under the Creative Commons Attribution International License (CC BY). http://creativecommons.org/licenses/by/4.0/

(c) (i) Open Access

\begin{abstract}
Pyogenic granuloma is a rapidly growing hyperplastic, vascular proliferation of the skin or mucous membrane. A benign lesion of unknown aetiology commonly associated with pregnancy, oral contraceptives and trauma. While lesions occur frequently in oral cavity, occurrence in the nasal septum is rarely reported. We report a case of 38-year-old male (known case of active pulmonary tuberculosis on anti-tubercular therapy) who presented with unilateral pyogenic granuloma of the anterior nasal septum with unilateral nasal obstruction. We emphasize that the rarely seen lobular capillary hemangioma (pyogenic granuloma) must be kept in mind in the differential diagnosis of a rapidly growing mass of the nasal cavity, even without history of epistaxis. Here we report an uncommon case and review current literature regarding aetiology, site and role of rifampicin in pyogenic granuloma.
\end{abstract}

\section{Keywords}

Pyogenic Granuloma, Nasal Obstruction, Vestibule

\section{Introduction}

Pyogenic granuloma of nasal cavity is also known as lobular capillary hemangioma, epulis gravidarum, eruptive hemangioma, granulation tissue-type hemangioma, granuloma gravidarum, pregnancy tumour, botryomycome [1] [2]. The various names of this tumour show that the exact pathogenesis continues to be debated. Some theories postulate that it has an association with injury and hormonal factors. In the nasal cavity, anterior septum is the most frequently affected followed by turbinate, but lesions have also been described arising from the maxillary sinus, roof of nasal cavity and floor of nasal vestibule. Pyogenic granuloma usually presents as epistaxis and

${ }^{*}$ Corresponding author.

How to cite this paper: Anil Kumar, R., Mahesh Babu, M., Venkatarajamma, P.R. and Mishra, U. (2014) Pyogenic Granuloma of Nasal Septum: A Case Report and Review of Literature. International Journal of Otolaryngology and Head \& Neck Surgery, 3, 190-194. http://dx.doi.org/10.4236/ijohns.2014.34035 
unilateral nasal obstruction. Histologically, these masses are characterized by varying sized capillaries in lobular arrangements and anastomosing networks of capillaries, thus supporting the name lobular capillary hemangioma [3]. Surrounding these lobules is a loose spindle cell proliferation of pericytic cells. Surgical excision is the treatment of choice for pyogenic granuloma [3].

\section{Case Report}

A 38-year-old male presented with nasal obstruction and a visible mass in the left nasal cavity of two weeks duration. He complained of nasal obstruction due to the increasing size of mass becoming progressively severe over a week period. There was no history of trauma, nasal packing and/or irritation. The patient was on anti-tubercular therapy (ATT) for pulmonary tuberculosis as per RNTCP (Revised National Tuberculosis Control Program) guidelines of a "new case". He had completed a 2 months intensive phase of ATT which includedIsoniazid (300 mg), Rifampicin (450 mg), Pyrazinamide (1500 mg) and Ethambutol (1200 mg) thrice-weekly. This was to be followed by a continuation phase of Rifampicin $(450 \mathrm{mg}$ ), and Pyrazinamide (1500 mg) for a period of 6 months thrice-weekly. The patient at the time of presentation was on the $3^{\text {rd }}$ month of continuation phase. Physical examination revealed a large, dark reddish polypoid mass in the left nasal cavity, insensitive to touch and this did not bleed on manipulation. It originated from the anterior portion of the septal mucosa about 3 $\mathrm{mm}$ posterior to the left vestibule, extended to the nasal vestibule completely obstructing the nasal orifice (Figure 1). Complete removal of nasal mass was done under local anesthesia by cauterization of the base with a unipolar electro-cautery with minimal blood loss. The mucosal defect thus created was $2 \mathrm{~mm} \times 1 \mathrm{~mm}$ in size; thedefect was left for free epithelialization. On gross examination, a smooth-surfaced, grayish-pink polypoid mass was approximately $10 \times 15 \times 5 \mathrm{~mm}$ in size (Figure 2). At histopathology revealed a polypoid mass of angiomatous tissue protruding above the surrounding mucosa. Pseudostratified ciliated epithelium covered the entire lesion, and some parts were eroded. Lobules of dilated and congested capillaries were noted. There was profound inflammatory cell infiltration (Figure 3(a) and Figure 3(b)). Post-operative period was uneventful.

\section{Review of Literature}

Pyogenic granuloma was first described as "human botryomycosis" by Poncet and Dor in 1897, and later in 1974 Haetzell coined the term "pyogenic granuloma" [1] [2]. However, the term is not representative of the underlying histopathology. The microscopic findings of pyogenic granuloma consist of proliferation of capillaries, and there are no pyogenic or infectious entities, nor are there macrophage-laden or granulomatous features. Hence, the term "lobular capillary hemangioma" as described by Mills et al. [4] is more appropriate. Despite this, the term "pyogenic granuloma" is still commonly used in most scientific literature. Patrice et al. in their series of

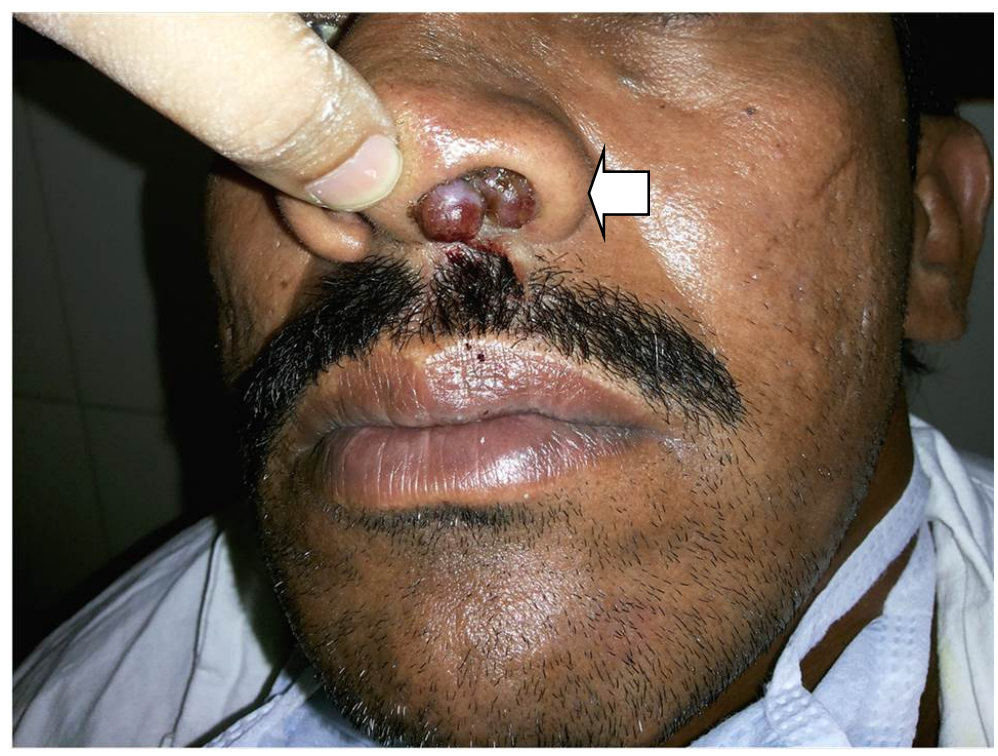

Figure 1. Arrow showing dark reddish polypoid mass in the left nasal cavity. 


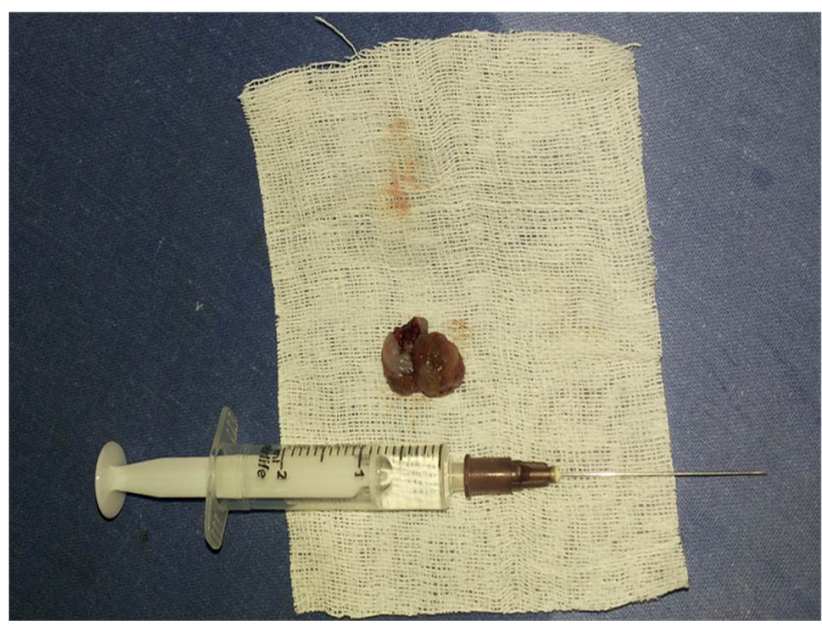

Figure 2. A smooth-surfaced, greyish-pink polypoid mass measuring approximately $10 \times 15 \times 5 \mathrm{~mm}$.

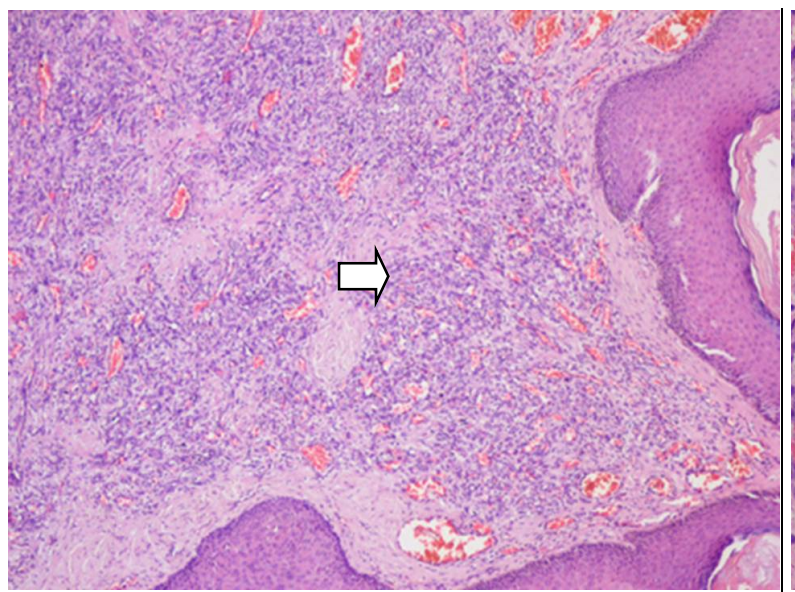

(a)

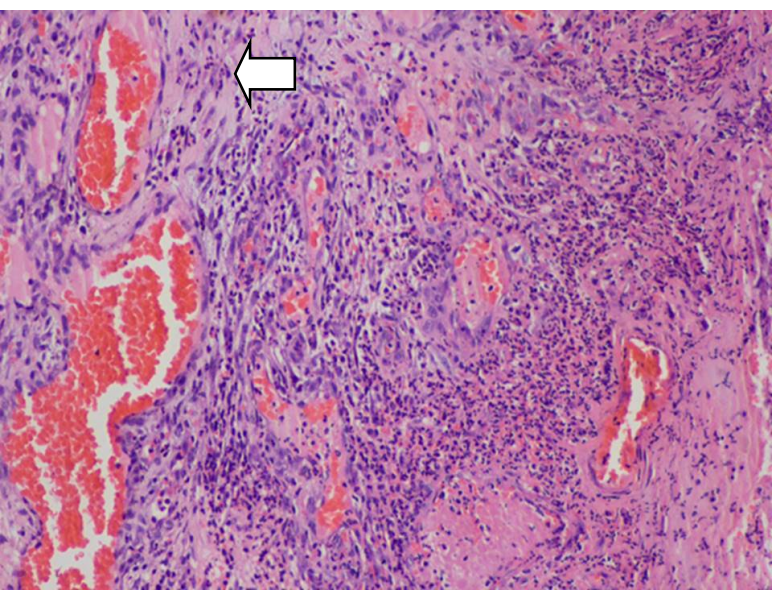

(b)

Figure 3. Histology showing lobules of dilated and congested capillaries with profound inflammatory cell infiltration (H \& E) in $40 \times$ and $100 \times$ respectively.

178 patients, reported that the head and neck area, particularly the oral cavity accounted for the most common sites involved (62.4\%) [5]. Nasal cavity [4] [5] was involved in only 7\% - 10\% of their patients; with the anterior portion of the septal mucosa and the tip of the turbinate being the most commonly involved areas.

The pathogenesis of pyogenic granuloma still remains unclear [4]-[6]. While it is accepted that trauma is a common cause of pyogenic granuloma, a series by Patrice et al. found that only $7 \%$ of patients had preceding history of nasal trauma [4]. Habitual nasal picking, prolonged contact with irritating agents from nasal packing [7] [8], nasogastric tube [9], foreign body or nose piercing [10] have all been reported to induce trauma. Pyogenic granuloma can also occur in association with increased levels of estrogen and progesterone as seen during pregnancy. The reported incidence during pregnancy ranges from less than 2 percent to approximately 5 percent [11]. Development of pyogenic granuloma in our patient could have been probably due to habitual nasal picking.

Pyogenic granuloma occurs at all ages, but more often in the third decade, and is more common in females. In the paediatric age group, pyogenic granuloma commonly affects males [2] [4].

Symptomatic manifestations of pyogenic granuloma include unilateral epistaxis (95\%), nasal blockage (35\%), rhinorrhoea (10\%), facial pain (7.5\%), headache and hyposmia (4\%) [2]. Pyogenic granuloma commonly presents as a red-purple coloured mass, lobulated, broad-based or pedunculated; $<10 \mathrm{~mm}$ in diameter, and may become ulcerated due to exposure to trauma, with variation in size. Though insidious in onset, full growth may be 
attained in 4 to 6 weeks. Growth seems to be self-limited. It has been observed that if snipped off by the patient, the tumour will recur. It is usually not painful and is non-tender on manipulation.

Complications of pyogenic granuloma are cosmetic and functional. They depend on the location, size or rapid proliferating phase of the neoplasm. Some type of complication is found in $40 \%$ of lesions, the commonest being bleeding (75\%) and ulceration (21\%) [12].

The differential diagnosis of tubercular intranasal pyogenic granuloma which includes nasal polyp, sarcoidosis, Wegener's granulomatosis, simple granulation tissue, papilloma, Kaposi's sarcoma, squamous cell carcinoma, mucosal malignant melanoma and lymphoma.

Radiological evaluation (computed tomography or magnetic resonance imaging) is only indicated has as complementary test to nasal endoscopic examination in large lesions especially those involving the skull base, or rapidly enlarging mass with evidence of bony erosion to exclude malignancy [12]. In our case, as the origin of the mass was clearly identified with endoscopy and limited to the anterior nasal septum, imaging study was deemed unnecessary.

Total excision of the lesion by either classical or endoscopic surgery techniques has been recommended [2] [3]. Endoscopic surgery provides better visualization of the mass and surrounding anatomy, thus allowing the surgeon to remove the mass completely without an external incision. In the very recent literature, all patients with a large lesion have been managed without preoperative embolization and none have experienced blood loss requiring transfusion. Recurrences are uncommon, and no malignant transformations have been reported [2] [3] [6].

Michel Noubom et al. [13] presented the possibility of treatment of this disease with the combination of rifampicin and dapsone for countries with limited income or in conditions where patient denies surgery for a period of one month (the authors in this study have not mentioned the dosage of rifampicin and dapsone administered). But in our case the patient in spite of being on rifampicin before and during the course of disease developed pyogenic granuloma. The role of rifampicin as a treatment option, its dosage and interaction with dapsone in the course of treatment of pyogenic granuloma needs further evaluation.

\section{Conclusion}

We have reviewed the literature of pyogenic granuloma of nasal septum and reported a rare case of nasal septum pyogenic granuloma in an adult male with active pulmonary tuberculosis on anti-tubercular treatment. Failure to recognize the clinical features and histopathological characteristics can lead to confusion with other forms of hemangioma or granulating lesions. Complete excision can be curative. The role of rifampicin and its dosage still requires further study before establishing it as a recognized treatment option. Therefore, pyogenic granuloma should be considered in the differential diagnosis of any anterior nasal septum mass even without associated epistaxis.

\section{References}

[1] Poncet, A. and Dor, L. (1897) Botryomycose Humaine. Rev Chir (Paris), 18, 996.

[2] Hartzell, M.B. (1974) Granulation Pyogenicum (Botryomycosis of French Authors). J Cutaneous Dis, 22, $520-523$.

[3] Puxeddu, R., Berlucchi, M., Ledda, G.P., Parodo, G., Farina, D. and Nicolai, P. (2006) Lobular Capillary Hemangioma of the Nasal Cavity: A Retrospective Study on 40 Patients. American Journal of Rhinology, 20, 480-484. http://dx.doi.org/10.2500/ajr.2006.20.2878

[4] Mills, S.E., Cooper, P.H. and Fechner, R.E. (1980) Lobular Capillary Hemangioma: The Underlying Lesion of Pyogenic Granuloma. A Study of 73 Cases from the Oral and Nasal Mucous Membranes. The American Journal of Surgical Pathology, 4, 470-479. http://dx.doi.org/10.1097/00000478-198010000-00007

[5] Patrice, S.J., Wiss, K. and Mulliken, J.B. (1991) Pyogenic Granuloma (Lobular Capillary Hemangioma): A ClinicoPathologic Study of 178 Cases. Pediatric Dermatology, 8, 267-276. http://dx.doi.org/10.1111/j.1525-1470.1991.tb00931.x

[6] Requena, L. and Sangueza, O.P. (1997) Cutaneous Vascular Proliferation, Part II. Hyperplasias and Benign Neoplasm. Journal of the American Academy of Dermatology, 37, 887-922. http://dx.doi.org/10.1016/S0190-9622(97)70065-3

[7] Bhattacharyya, N., Wenokur, R.K. and Goodman, M.L. (1997) Endoscopic Excision of a Giant Pyogenic Granuloma of the Nasal Cavity Caused by Nasal Packing. Rhinology, 35, 44-45.

[8] Lee, H.M., Lee, S.H. and Hwang, S.J. (2002) A Giant Pyogenic Granuloma in the Nasal Cavity Caused by Nasal 
Packing. European Archives of Oto-Rhino-Laryngology, 259, 231-233. http://dx.doi.org/10.1007/s00405-001-0442-x

[9] Neves-Pinto, R.M., Carvalho, A., Araujo, E., Alberto, C., De Oliveira, B. and De Carvalho, G.A. (2005) Nasal Septum Giant Pyogenic Granuloma after a Long Lasting Nasal Intubation: Case Report. Rhinology, 43, 66-69.

[10] Kumar Ghosh, S. and Bandyopadhyay, D. (2012) Granuloma Pyogenicum as a Complication of Decorative Nose Piercing: Report of Eight Cases from Eastern India. Journal of Cutaneous Medicine and Surgery, 16, 197-200.

[11] Delbrouck, C., Chamiec, M., Hassid, S. and Ghanooni, R. (2011) Lobular Capillary Haemangioma of the Nasal Cavity during Pregnancy. Journal of Laryngology and Otology, 125, 973-977.

[12] Chiller, K.G., Passaro, D. and Frieden, I.J. (2002) Hemangiomas of Infancy: Clinical Characteristics, Morphologic Subtypes, and Their Relationship to Race, Ethnicity and Sex. Archives of Dermatology, 138, 1567-1576. http://dx.doi.org/10.1001/archderm.138.12.1567

[13] Noubom, M., Kenfack, B., Donfack, J.H., Nembot, F.D. and Sando, Z. (2013) Clinical Case of Botryomycome Fulminant at the Center of Diagnostic and Treatment of Tuberculosis of Baleng (West-Cameroon). The Pan African Medical Journal, 14, 131. 
Scientific Research Publishing (SCIRP) is one of the largest Open Access journal publishers. It is currently publishing more than 200 open access, online, peer-reviewed journals covering a wide range of academic disciplines. SCIRP serves the worldwide academic communities and contributes to the progress and application of science with its publication.

Other selected journals from SCIRP are listed as below. Submit your manuscript to us via either submit@scirp.org or Online Submission Portal.
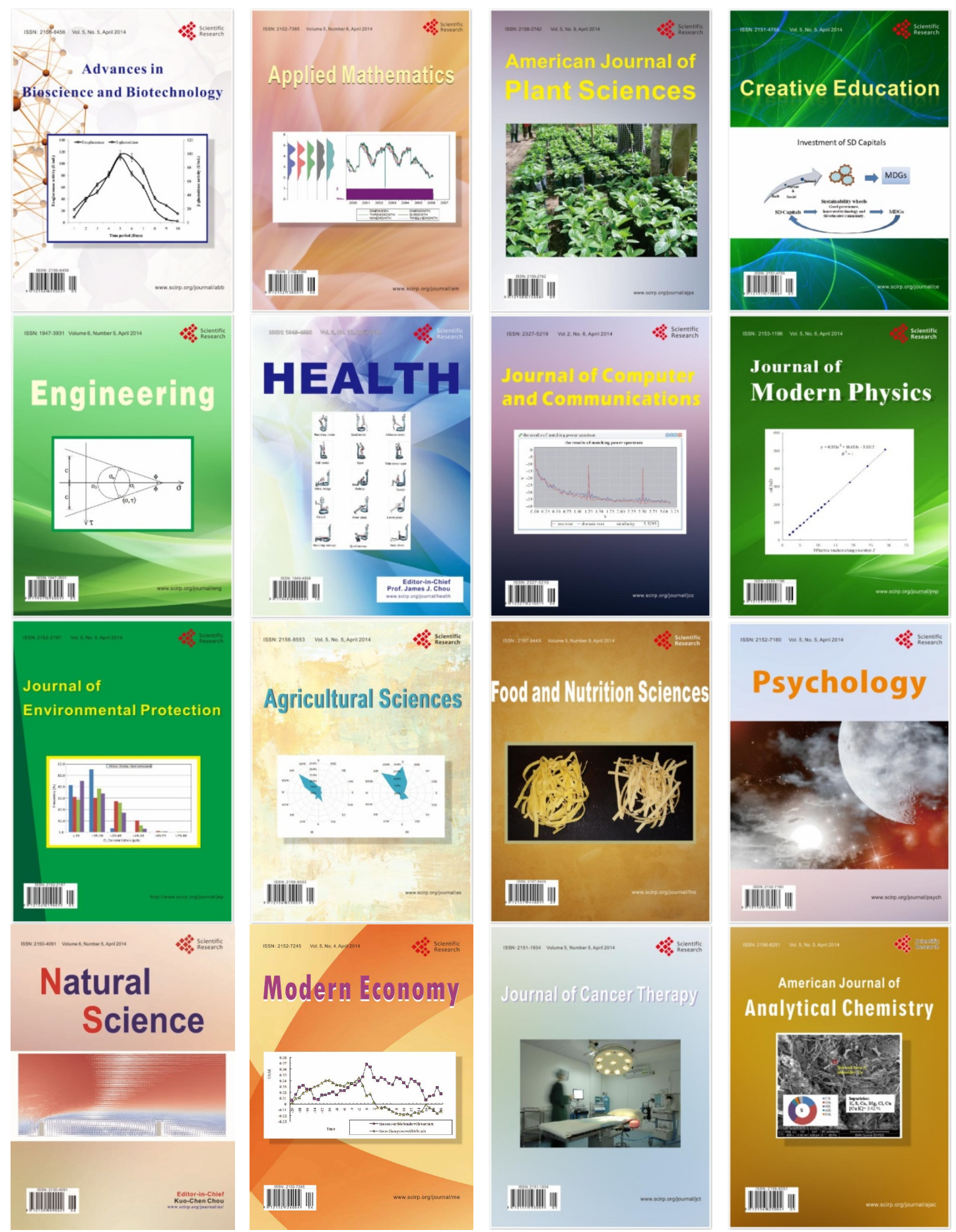